\title{
CARTOGRAFIA DA LUSOFONIA DE LÍNGUA PORTUGUESA NO MUNDO E EM TIMOR-LESTE
}

\section{CARTOGRAPHY OF THE LUSOPHONY IN THE PORTUGUESE LANGUAGE IN THE WORLD AND IN EAST-TIMOR}

\author{
Vicente Paulino* \\ Universidade Nacional Timor Lorosa'e. Díli - Timor-Leste \\ Universidade Aberta, Lisboa, Portugal
}

\begin{abstract}
Resumo: Neste artigo, procuramos refletir sobre a perspectiva de consolidação da língua portuguesa em Timor-Leste, sempre norteada pelos discursos políicos e discursos dos cooperantes que ofereceram e ainda oferecem a sua prestação de serviço ao ensino timorense em e na língua portuguesa. Além disso, as narrativas do artigo são enriquecidas também pelas modalidades teóricas com a junção de dois conceitos como "lusofonia" e "consciência nacional" em torno do património imaterial da língua portuguesa. Nossas considerações apontam para o resultado de introdução e consolidação do português enquanto língua oficial de Timor em todas as linhas de ações, nomeadamente no setor de administração pública, no setor da educação, no setor da igreja e no setor da média.
\end{abstract}

Palavras-chave: Timor-Leste; Língua Portuguesa; Consciência nacional; Lusofonia.

\begin{abstract}
The aim of this article is to reflect on the perspective of the Portuguese-language consolidation in East Timor, which has always been guided both by the political and the volunteers discourses who offered and still offer their service to Timorese teaching in the Portuguese language. In addition, the narratives of the article are also enriched by theoretical modalities merged with two concepts which are "Lusophony" and "national consciousness" around the intangible heritage of the Portuguese language. The main assertion of this article is the result of introducing and consolidating Portuguese as the official language of Timor in all strand of action, namely in the public administration sector, the education sector, the church sector, and the media sector.
\end{abstract}

Keywords: East Timor; Portuguese Language; National Consciousness; Lusophony.

* Universidade Nacional Timor Lorosa'e - UNTL, Díli, Timor-Leste; Universidade Aberta, Lisboa, Portugal; vicentepaulino123@gmail.com

http://dx.doi.org/10.11606/issn.2236-4242.v32i2p145-167 
Linha D'Água (Online), São Paulo, v. 32, n. 2, p. 145-167, maio-ago. 2019

\section{Introdução}

Como indicado no título, este artigo constitui um estudo sobre a cartografia da lusofonia de língua portuguesa que está em grande expansão desde o tempo de descobrimentos. A língua portuguesa não é apenas falada pela Comunidade dos Países de Língua Portuguesa (CPLP), mas falada também por aqueles que têm uma "parcela de história" partilhada no passado.

\section{Assim escrevia o grupo Da Vinci na Revista Eurovisão em 1989,}

Era um mundo novo / Um sonho de poetas / Ir até ao fim / Cantar novas vitórias /E erguer, orgulhosos, bandeiras / Viver aventuras guerreiras / Foram mil epopeias / Vidas tão cheias /Foram oceanos de amor / Já fui ao Brasil / Praia e Bissau / Angola, Moçambique / Goa e Macau / Ai, fui até Timor/ Já fui um conquistador / Era todo um povo / Guiado pelos céus /Espalhou-se pelo mundo /Seguindo os seus heróis / Elevaram a luz da tortura/ Semearam laços de ternura Foram dias e dias e meses e anos no mar / Percorrendo uma estrada de estrelas a conquistar (obs cit Lança, 2010) ${ }^{1}$.

Vale a pena realçar como base da abordagem do tema "cartografia da lusofonia de língua portuguesa" três tempos considerados pelo Adriano Freixo (2009), como um marco histórico na formulação da ideia de criação "comunidade lusófona":

década de 1950, na qual diversos intelectuais brasileiros e portugueses, de matizes ideológicos diversos - como Gilberto Freyre, Joaquim Barradas de Carvalho, Adriano Moreira, Agostinho da Silva e Darcy Ribeiro - tematizam a ideia de uma “comunidade lusófona" ou "lusíada"; o ano de 1989, com a criação, no Maranhão, do Instituto Internacional de Língua Portuguesa (IILP), marcando a inserção mais ativa do Brasil na defesa da proposta, assim como a necessidade premente, por parte de Portugal, de um suposto "regresso à África"; e, por fim, a efetiva criação, em 1996, da CPLP (FREIXO, 2009 - obs cit MARTINS, 2011, p. 156).

1 Marta Lança (2008), A lusofonia é uma bolha. Disponível em http://www.buala.org/pt/jogos-sem-fronteiras/a-lusofonia-e-uma-bolha. Acesso disponível em 15 mai. 2018.

PAULINO, V. Cartografia da lusofonia de língua portuguesa no mundo e em Timor-Leste 
Para atingir nossos objetivos, dividimos este artigo em quatro partes: primeiramente, apresentaremos uma cartografia da lusofonia de língua portuguesa, incluindo nela timor leste; em seguida em nós portugueses, outros nós e a lusofonia: que consciência da lusofonia é essa? discutiremos nossa posição no espaço lusófono; na sequência, em discurso sobre a lusofonia em Timor-Leste, defendemos a adoção e consolidação da LP em timor; por fim, em aprender o português é uma questão de consciência nacional e patriótica, defendemos o ensino aprendizagem da LP em Timor.

Em Timor-Leste, o português ainda não está bem consolidado, apesar de sua existência como língua oficial bem como língua de instrução e de administração. Trata-se de um problema que deve e pode ser tomado em consciência como um assunto de afirmação da identidade cultural e nacional do povo timorense.

Se o português é uma língua oficial de Timor-Leste, cada cidadão tem obrigação de aprender esta língua como se fosse corpo de sua alma, ou seja, um elemento identitário que faz diferenciar o nós timorenses do de outros países vizinhos - Indonésia e Austrália. Se cada cidadão timorense compreende o sentido de "nós timorenses" em e na língua portuguesa, então, o que é mais útil é fazer um inventário sobre a existência dessa língua, desde a sua entrada até a sua permanência como língua oficial.

O mais compreensivo possível dos problemas de consolidação do português em Timor-Leste está na falta de consistência política por parte de alguns políticos, nomeadamente aqueles que estão no serviço da educação (incluindo alguns deputados) que não se interessem com a importância da língua portuguesa oficializada e consagrada na Constituição da República Democrática. Além disso, a própria cooperação dos países lusófonas - nomeadamente alguns professores cooperantes do Instituto Camões em Timor-Leste, destacados no Centro de Língua Portuguesa da Universidade Nacional Timor Lorosa e - também não colaboram eficazmente na consolidação desta língua camoniana.

É necessário, portanto, conhecer novas formas para resolver o problema da consolidação do português em questão, usando a expressão "vamos difundir o português" no seio do povo de Timor-Leste. Para tal, é preciso conhecer e compreender a noção de lusofonia ou lusofoneidade no seu restrito e amplo sentido, porque 
Linha D'Água (Online), São Paulo, v. 32, n. 2, p. 145-167, maio-ago. 2019

muitas vezes os portugueses - nos discursos políticos e nas conversas do café - dizem assim: nós e lusofonia. Trata-se de uma atitude que desvaloriza a sua integração na comunidade lusófona, é um problema da "agenda moral" de se imaginarem superiores aos outros países falantes de língua portuguesa. É um ego que deve ser combatido com a concertação política no quadro da CPLP, usando o discurso voltado à lusofonia que tem base na performance de interculturalidade.

\section{Uma cartografia da lusofonia de língua portuguesa}

A lusofonia é talvez uma ilusão, mas reais e bem concretos são os vestígios da presença portuguesa no Mundo. Vestígios de uma ilusão, de um sonho que levou Portugal à descoberta de outros Mundos. Ela não é nem pode ser comparável à Francofonia, nem à Commonwealt quer seja a nível político ou económico. O seu único poder e marca de união é a língua camoniana. Portanto,

Não há razão para não sonhar a sério - mesmo com os perigos de delírio que comporta - uma comunidade de raiz linguisticamente portuguesa (...), sonhá-la a sério significa não ser o único sonhador dela e saber que os outros não a sonham como nós (LOURENÇO 1999:165).

Compreende-se desta forma que a lusofonia é um espaço simbólico que reúne o conjunto de identidades culturais existentes em países, regiões, estados ou cidades falantes da língua portuguesa, com objectivos de desenvolvimento político, económico e social, baseado no respeito pelos valores humanos e da soberania de cada Estado-nação e pela promoção da língua portuguesa, sendo esta considerada como denominador comum dos seus membros. Apesar de ter sido classificado mundialmente como países de baixo poder económico e político entre outros países, não se esgota o seu poder de união, isto é, utilizando a sua força que é a língua portuguesa enquanto símbolo de união, para reafirmar a sua ligação na grande comunidade imaginada, a "lusofonia".

Ser lusófono é, de certeza, mais do que ser falante de língua portuguesa. Ser lusófono significa ser do mundo ou, na afirmação de Vergílio Ferreira, da "minha língua vê-se o mar" e com ela "se vê o mundo e em que se traçam os limites do nosso 
pensar e sentir", a qual Miguel Torga advertia como "um traço de união" entre povos. A história de diferentes povos agrupados no teto da lusofonia é unida pela língua e religião. A língua portuguesa e o cristianismo são fundamentais na afirmação da identidade colectiva e são parte indissociável do imaginário lusófono da CPLP, a razão pela qual Fernando Cristóvão (2014) insista sempre que na definição de "lusofonia" só é válido o conceito "língua do luso/português" e nunca a generalização neocolonialista de "expressão portuguesa”. Assim, os oito países lusófonos que nas suas Constituições políticas, definem o português como sua língua oficial, devem entendê-la só como língua comum, e não como expressão cultural lusitana.

É a língua portuguesa que nos faz iguais e diferentes em diversas dimensões de viver. Faz-nos diferentes do outro é uma forma de dizer que "somos povo único" entre outros. Isso é que se chama a magia da cartografia da lusofonia fundamentada pelas profundas trocas da alma (refere-se à produção de vida sustentada pelo conceito de mestiçagem) e trocas simbólicas de culturas. Todavia, a cartografia da lusofonia pode ser entendida, de certa forma, como uma rota de expansão do português no mundo onde se entrelaça o encontro entre estranhos povos. Ou seja, se se permite recorrer à fala do romancista timorense Luís Cardoso, a cartografia da lusofonia é definida desta forma:

Foi no ano da minha quarta classe que descobri o caminho do retorno dos descobrimentos. Macau e a Cidade do santo nome de Deus. Goa, Damão e Diu, Índia chorada. Moçambique comprido como a girafa do parque do Gorongosa. Angola grande dos diamantes das Lundas e do petróleo de Cabinda. São Tomé e Príncipe do Mário Lopes e do cacau. Guiné e o arquipélago dos Bijagós. Cabo Verde e a morna do Mindelo. A Madeira e o arquipélago dos Açores. Brasil e o grito do Ipiranga. A metrópole e o Entroncamento onde se cruzavam todos os comboios do mundo. Às vezes tinha dúvidas sobre a existência destas terras, lembrando as suspeitas da minha mãe. Mas o encanto fazia-me acreditar em tantas coisas distantes como no paraíso perdido pelo Adão e ganho pela morte. Eu deveria acreditar também em paraísos terrenos mais próximos e mais vivos. (2002, p. 58).

Se for assim, alguma vez a lusofonia penetrou nas bandas do mar de Arafura, da banda das ilhas especiarias do arquipélago malaio e da costa norte da Austrália? Claro que penetrou, embora a sua permanência tenha ficado apenas poucos 
tempos, como se lê em Cardoso (2007, p. 11): "todos aqueles que antes de mim foram passando por estas bandas do mar de Arafura, uns em busca de sol, outros de aventura, duma terra prometida, duma fragrância, de uma alma gémea ou do que faz falta na vida de cada um" (CARDOSO, 2007, p. 11).

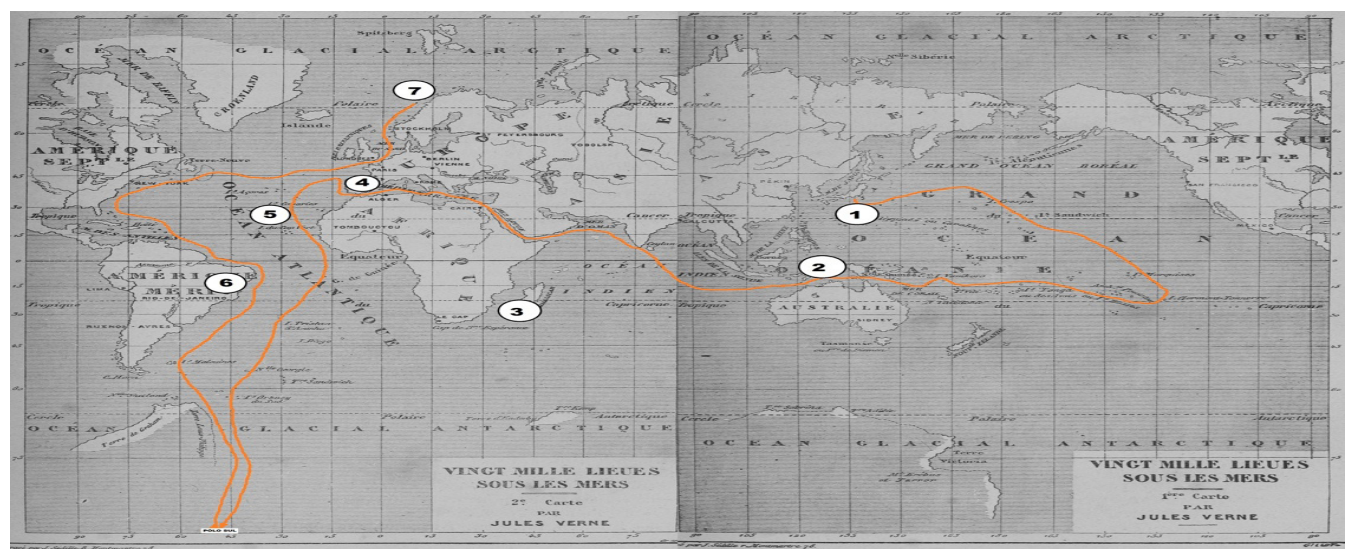

Fig. 1: O Mapa de Nautilus de Júlio Verne e as terras da lusofonia²

A lusofonia representa os espaços da língua lusa, lusitana ou portuguesa; ela é em termos concretos, usada para identificar as diferentes cidades e diferentes países que partilham a mesma história. Em termos abstractos, o conceito de lusofonia assemelha-se ao conceito de espiritualidade da alma fundamentada na mensagem pessoana do "quinto império", e é nesse império que se vê "minha língua" e "minha pátria”. Trata-se de uma junção de expressão de Fernando Pessoa e Vergílio Ferreira na afirmação do ser lusitano que leva a sua língua pelo mar fora, navegando para além-do-mar até ao encontro da terra de outros povos. É uma dimensão de hibridização cultural no quadro do "terceiro espaço" de trocas simbólicas das ideias e das culturas diferenciadas.

\footnotetext{
2 Este mapa mostra a viagem percorrida pelo Júlio Verne com o barco submarino conhecido por Nautilus. O Nautilus quando se moveu na superfície do oceano, fez a primeira passagem em terras que falavam português, e que surgiu na primeira instância foi a norte da Oceânia, daí passando pela ilha de Timor. Como se pode constatar também com o percurso marcado no mapa, o barco Nautilus passou pela Índia e daí dirigia-se ao Golfo Pérsico em direção ao Moçambique - in CrónicasPortuguesas-https://cronicas-portuguesas.blogspot.com/2012/07/o-nautilus-de-julioverne-e-as-terras. $h t m l$ ? m=1. Acesso disponível em 15 mai. 2018.
}

PAULINO, V. Cartografia da lusofonia de língua portuguesa no mundo e em Timor-Leste 
Quando se define a cartografia da lusofonia, precisa-se conjugar a ideia de espiritualidade e a ideia da razão, através de um processo de selecção dos fatos de descobrimentos dos territórios que ainda hoje estão a ser recordados graças a concertação política da própria CPLP. Daí compreende-se que a cartografia da lusofonia é resultado de uma representação de “imensa Lusitânia" em território das colónias portuguesas e do mundo, assim a melhor definição seria: a) a Lusitânia Antiga, representada por Portugal enquanto berço linguístico-cultural de todo o grupo; b) a Lusitânia Nova, simbolizada pelo Brasil; c) a Lusitânia Novíssima, formada pelos países africanos de língua oficial portuguesa e Timor-Leste; e) a Lusitânia Perdida, ou seja, os antigos territórios de língua portuguesa (como Macau, Goa, entre outros); d) a Lusitânia dispersa, refere-se a comunidade falante de língua portuguesa espalhada pelo mundo (MARTINS, 2011, p. 27).

É este mundo da lusofonia que alguns defendem de forma contraditória e de mútuo entendimento, desde a Auto da Lusitânia de Gil Vicente (1531) até o luso-tropicalismo de Gilberto Freyre (1940) que ofereceu um novo paradigma de política ultramarina de Salazar, onde se destacou o espírito de "portugalidade português” através da estranha cerimónia para afirmar a presença portuguesa no mundo, que naturalmente, feita pela afeição de plasticidade da mistura, isto é, a manutenção das colónias ao poder da metrópole. Embora já tenha havido muitas críticas sobre esse novo paradigma discursivo de Salazar (Cf. Sousa, 2011), pelo que parece relacionar-se com o poder e a obediência baseados em uma teoria do consentimento que os homens propõem aplicar como um direito, ainda que sujeito aos mais variados condicionamentos. Começaria pela afirmação de salazar (neste mundo da lusofonia em que se constroi um novo paradigma de política ultramarina, destaca-se oo espírito de portugalidadena manutenção do poder da metrópole:

No meio das convulsões presentes, nós apresentamo-nos como uma comunidade de povos, cimentada por séculos de vida pacífica e compreensão cristã, irmandade de povos que, sejam quais forem as suas diferenciações, se auxiliam, se cultivam e se elevam, orgulhosos do mesmo nome e qualidade de portugueses (discurso de Salazar em 1933 - obs cit LANÇA, 2010)³.

3 Marta Lança (2008), A lusofonia é uma bolha. Disponível em http://www.buala.org/pt/ jogos-sem-fronteiras/a-lusofonia-e-uma-bolha. Acesso disponível em 15 mai. 2018.

PAULINO, V. Cartografia da lusofonia de língua portuguesa no mundo e em Timor-Leste 
Enfim, o paradigma discursivo de Salazar ficou apenas na gaveta da história, pois a revolução de 25 de Abril de 1974 aboliu o tal discurso do poder. Não tardou muito, porém, já na década de 1980, começou a estabelecer-se um laço de proximidade afetiva entre Portugal e ex-colónias sob a ordem do discurso da lusofonia (Freixo, 2009).

A cartografia da lusofonia é vista pela própria definição da "cartografia linguística" e da distribuição geográfica e étnica das línguas que se unem no mapeamento de língua portuguesa. Trata-se de uma galáxia gramatical exibida na praça da língua, onde o elogio é feito com a festa dessa própria língua falada por todo o mundo. Além disso, tal cartografia da lusofonia é definida e identificada pela descrição da "cartografia de imagens" e da "cartografia dos monumentos históricos" sobre o mapeamento de povoação rudimentar dos portugueses no seio das comunidades que os acolheram, por exemplo, a fortaleza de Solor na ilha das Flores, a fortaleza de Malaca.

Trata-se também do número de falantes e do número de utilizadores da internet no mundo. Trata-se de uma "galáxia falativa navegante" no mapeamento linguístico e tecnológico, pois entende-se que o mundo está a intensificar-se pelas gigantescas redes conhecidas por World-wide na relação social da sociedade (PAULINO, 2015a; PAULINO, 2012).



Fig. 2: O número de falantes do português em 2050 (Reto et alii, 2016) 
Linha D'Água (Online), São Paulo, v. 32, n. 2, p. 145-167, maio-ago. 2019

\begin{tabular}{|c|c|c|c|c|c|}
\hline \multicolumn{6}{|c|}{$\begin{array}{c}\text { Top Ten Languages Used in the Web - December } \mathbf{3 1 ,} 2017 \\
\text { (Number of Internet Users by Language) }\end{array}$} \\
\hline $\begin{array}{l}\text { TOP TEN LANGUAGES } \\
\text { IN THE INTERNET }\end{array}$ & $\begin{array}{l}\text { World Population } \\
\text { for this Language } \\
\text { (2018 Estimate) }\end{array}$ & $\begin{array}{l}\text { Internet Users } \\
\text { by Language }\end{array}$ & $\begin{array}{l}\text { Internet } \\
\text { Penetration } \\
\text { (\% Population) }\end{array}$ & $\begin{array}{l}\text { Internet } \\
\text { Users Growth } \\
(2000-2018)\end{array}$ & $\begin{array}{l}\text { Internet Users } \\
\% \text { of World } \\
\text { (Participation) }\end{array}$ \\
\hline English & $1,462,008,909$ & $1,052,764,386$ & $72.0 \%$ & $647.9 \%$ & $25.3 \%$ \\
\hline Chinese & $1,452,593,223$ & $804,634,814$ & $55.4 \%$ & $2,390.9 \%$ & $19.4 \%$ \\
\hline Spanish & $515,759,912$ & $337,892,295$ & $65.5 \%$ & $1,758.5 \%$ & $8.1 \%$ \\
\hline Arabic & $435,636,462$ & $219,041,264$ & $50.3 \%$ & $8,616.0 \%$ & $5.3 \%$ \\
\hline Portuguese & $286,455,543$ & $169,157,589$ & $59.1 \%$ & $2,132.8 \%$ & $4.1 \%$ \\
\hline Indonesian / Malaysian & $299,271,514$ & $168,755,091$ & $56.4 \%$ & $2,845.1 \%$ & $4.1 \%$ \\
\hline French & $127,185,332$ & $118,626,672$ & $93.3 \%$ & $152.0 \%$ & $2.9 \%$ \\
\hline Japanese & $143,964,709$ & $109,552,842$ & $76.1 \%$ & $3,434.0 \%$ & $2.7 \%$ \\
\hline Russian & $405,644,599$ & $108,014,564$ & $26.6 \%$ & $800.2 \%$ & $2.8 \%$ \\
\hline German & $94,943,848$ & $84,700,419$ & $89.2 \%$ & $207.8 \%$ & $2.2 \%$ \\
\hline TOP 10 LANGUAGES & $5,135,270,101$ & $3,206,613,856$ & $62.4 \%$ & $1,091 \%$ & $77.1 \%$ \\
\hline Rest of the Languages & $2,499,488,327$ & $950,318,284$ & $38.0 \%$ & $935 \%$ & $22.9 \%$ \\
\hline WORLD TOTAL & $7,634,758,428$ & $4,156,932,140$ & $54.4 \%$ & $1,051 \%$ & $100.0 \%$ \\
\hline \multicolumn{6}{|c|}{$\begin{array}{l}\text { NOTES: (1) Top Ten Languages Internet Stats were updated in December } 31,2017 \text {. (2) Internet Penetration is the ratio } \\
\text { between the sum of Internet users speaking a language and the total population estimate that speaks that specific language. } \\
\text { (3) The most recent Internet usage information comes from data published by Nielsen Online, International } \\
\text { Telecommunications Union, GfK, and other reliable sources. (4) Population estimates are based mainly on figures from the } \\
\text { United Nations Population Division and local official sources. (5) For definitions, methodology and navigation help, please } \\
\text { see the Site Surfing Guide. (6) These statistics may be cited, stating the source and establishing an active link back to } \\
\text { Internet World Stats. Copyright (c) } 2018 \text {, Miniwatts Marketing Group. All rights reserved worldwide. }\end{array}$} \\
\hline
\end{tabular}

Fig. 3: Línguas mais usadas no web ${ }^{4}$

Portanto, a partir da cartografia da lusofonia, compreende-se a existência de um fluxo narrativo revelador de uma permanência do passado no presente e de previsão imaginária sobre o futuro da lusofonia no tempo que há-de-vir. Certo é que para compreender esta ideia da razão, necessita-se de uma vibração de impulso dos cidadãos falantes de língua portuguesa para construírem um fluxo continuado da lusofonia com a fórmula da "intransitividade dos verbos fluir e ressoar" (Martins, 2015, p. 35), para que "a língua portuguesa seja um objeto sem território específico, é um objecto em devir, sem centro, apenas com novas práticas de memória e sonho, por parte daqueles que a habitam, em Portugal, no Brasil, em Moçambique, ou em qualquer outro país de língua oficial portuguesa" (Martins, 2015, p. 36). A lusofonia é, certamente, que com circum-navegação temporal de Fernão de Magalhães na era de descobrimentos e até circum-navegação tecnológica na era de globalização, ou aquilo a que os franceses chamam mundialização. Daí pode perceber-se que a lusofonia é um espaço simbólico com "carácter operativo útil" para dar visibilidade ao mundo sobre a navegação de Vasco da Gama à Índia e até a navegação de António Pigafetta à Timor (CARDOSO, 2012; Paulino, 2017), com

4 Informação buscada em https://www.internetworldstats.com/stats7.htm Acesso disponível em 15 mai. 2018.

PAULINO, V. Cartografia da lusofonia de língua portuguesa no mundo e em Timor-Leste

Todo conteúdo da Linha D’Água está sob Licença Creative Commons Attribution-NonCommercial 4.0 International License 
Linha D'Água (Online), São Paulo, v. 32, n. 2, p. 145-167, maio-ago. 2019

uma curta-passagem, trocando alguns produtos provenientes da Índia e de Malaca com os sândalos de Timor (PAULINO, 2015).

\section{Nós portugueses, outros nós e a lusofonia: que consciência da lusofonia é essa?}

O projecto bilateral e multilateral de cooperação relativo à consolidação da língua portuguesa em todas escolas básicas e todos os dispositivos governamentais, em Timor, deve ser reforçado "não no sentido de arrogância intelectual", mas nas "acções afectivas" de dois e/ou mais países com elevado sentido de missão cultural. Uma vez que se enquadra no quadro legal dos acordos estabelecidos e tal contribui para "a difusão da língua portuguesa, bem como para o reforço dos especiais laços de amizade e solidariedade que ligam os dois Estados, assim como para o desenvolvimento cultural, científico e técnico de Timor-Leste, no quadro do respeito recíproco pelos valores culturais próprios e para um melhor conhecimento colectivo da ciência entre o povo português e o povo timorense e a intensificação das iniciativas que reforcem a mútua cooperação5".

A verificação destas realidades, a par do processo evolutivo das sociedades e das inerentes capacidades de intuição valorativa, conduz, designadamente, no plano das suas interacções e transacções culturais, a uma alteração das perspectivas sobre a percepção das necessidades de dois países e/ou países "parceiros estratégicos de desenvolvimento", em termos de interesses e consequente articulação destes com objectivos definidos por políticas de realização concreta da "diplomacia cultural" à génese de uma ordem regularmente reconhecida pela forma como o relacionamento se estabelece e se faz sentir.

Contudo, aqui em Timor-Leste, vê-se um ato chamado "lusofonia desonrada", querendo dizer que na modalidade cooperação internacional "alguns professores cooperantes" desvalorizam o "carácter operativo útil” do espírito lusitano

\footnotetext{
5 Ver o "ACORDO DE COOPERAÇÃO ENTRE A REPÚBLICA PORTUGUESA E A REPÚBLICA DEMOCRÁTICA DE TIMOR-LESTE NO DOMÍNIO DA COMUNICAÇÃOSOCIAL", feito em 22 de fev. 2006-http://d3f5055r2rwsy1.cloudfront.net/images/stories/acordos/timor_accs.pdf. Acesso disponível em 6 jun.2015.
}

PAULINO, V. Cartografia da lusofonia de língua portuguesa no mundo e em Timor-Leste 
na implementação do projecto de capacitação em língua portuguesa, já que, na prática, não se vê fisicamente o resultado obtido. Trata-se de uma modalidade de cooperação de desinteresse que talvez tenha vindo do facto de as práticas também remontarem ao passado, como explicita Marta Lança (2010):

Os agentes de promoção da lusofonia ainda funcionam como centro cultural na 'metrópole' que subsidia os vários representantes no terreno sem qualquer noção das realidades desses países, sem estratégia conjunta de programação, etc. O espaço lusófono acaba por ser a tal "bolha onde tudo é possível e tudo se consome", retomando a ideia de Lívia Apa, "um mundo criado pelo 'laço' da língua portuguesa, dentro do qual os escritores transitam, se movem, trocam visitas, falam, escrevem, são lidos, mas fora do qual eles próprios não conseguem encontrar o seu lugar, como se fossem até incapazes de ter acesso ao que acontece fora da lusofonia ${ }^{6}$.

Contudo, diz-se que somos povos irmãos unidos pela história, pela cultura e pela língua; mas "não parece que este reconhecimento exista, nem sequer esteja a ser fomentado" (Lourenço, 2014, p. 50) quando "dizemos que há um cordão umbilical linguístico entre nós, mas cada um só olha para a ponta dos seus sapatos" (GUSMÃO, 2013)7 e "se queremos dar sentido à galáxia lusófona" (BAPTISTA, 2000 - obs cit SOUSA, 2016, p. 35), e se aceitamos o "dever ser lusófono" (FIORIN, 2010, p. 21), temos de vivê-la harmoniosamente com todos aqueles que falam a mesma língua e partilham uma aproximação possível da história. É neste sentido que deve entender-se a lusofonia como um espaço de cultura e enquanto tal um timorense letrado frisa que "lusofonia é o laço que une o povo timorense aos outros países" que falam o português. A presença da lusofonia em Timor é representada através de músicas, danças e também da língua que esse povo fala" (BRITO; CAVALCANTE \& COSTA, 2016, p. 136). Portanto aqui se vê claramente o sentido do inconsciente colectivo lusófono que alimenta o sonho dos

6 Marta Lança (2008), A lusofonia é uma bolha. Disponível em http://www.buala.org/pt/jogos-sem-fronteiras/a-lusofonia-e-uma-bolha. Disponível em 15 mai. 2018.

7 Esta declaração foi dada pelo Xanana Gusmão na sua entrevista concedida à Agencia Noticiosa Lusa, a propósito da tomada de posse da presidência da CPLP, em julho do próximo ano, in Económico, 4/10/2013 - https://economico.sapo.pt/noticias/xanana-gusmao-quer-uma-cplp-um-cariz-mais-economico_178669.html Disponível em 15 mai. 2018.

PAULINO, V. Cartografia da lusofonia de língua portuguesa no mundo e em Timor-Leste 


\section{Linha D'Água (Online), São Paulo, v. 32, n. 2, p. 145-167, maio-ago. 2019}

timorenses na construção de sua identidade linguística, porque nela se esconde "coisas ditas" através do discurso "uma vez que se conservam um segredo ou uma riqueza" (FOUCAULT, 2007, p. 19). A característica da lusofonia pode ser

uma classificação prática que está subordinada a diversas funções para produzir efeitos sociais desejados. A sua força, em parte, decorre do facto de que a figura de lusofonia não é muito diferente da realidade social das distintas comunidades nacionais onde esta identidade simbólica é processada (cf. Martins, 2006) no contexto conceptual de discursos negociados (Vanspauwen, 2011, p. 71).

Quando alguns portugueses afirmam "nós portugueses e a lusofonia", podem dar a entender que os portugueses não pertencem à lusofonia, e então para que serve a lusofonia, se os próprios portugueses se consideram a si mesmos como não pertencentes à lusofonia? Lança adverte ainda que

Apesar do discurso aparentemente empenhado da lusofonia, na realidade não existe verdadeiramente uma consciência lusófona, não há lóbi lusófono na ONU ou na OMC (pelo menos se compararmos com a francofonia), nem tem assim tanta coesão, nem no plano económico nem político. Nem em termos de identidade: quase nenhum africano ou brasileiro se afirma enquanto 'lusófono' (só ouço portugueses falarem disso) ${ }^{8}$.

A propósito, importa recordar que, numa conferência "A lusofonia entre Encruzilhadas Culturais" realizadas em 24 a 25 de Fevereiro de 2011, alguns académicos argumentaram que a lusofonia é uma comunidade imaginada pelos portugueses e marcada por uma visão neo-colonial, como argumentava, na ocasião,Maria Manuel Baptista que esta é "uma mera organização que tem como único elo de ligação a cultura e a língua é uma das estratégias pelas quais considero que a lusofonia ainda não é uma realidade", e mais adianta que "os povos falantes de português não falam precisamente a mesma língua e são culturalmente muito diferentes, ao contrário do que a maior parte dos portugueses julga”. Por isso, para

8 Marta Lança (2008), A lusofonia é uma bolha. Disponível em http://www.buala.org/pt/ jogos-sem-fronteiras/a-lusofonia-e-uma-bolha. Disponível em 15 mai. 2018.

PAULINO, V. Cartografia da lusofonia de língua portuguesa no mundo e em Timor-Leste 
Linha D'Água (Online), São Paulo, v. 32, n. 2, p. 145-167, maio-ago. 2019

esta investigadora a ideia de se "pertencer à mesma pátria porque se tem a mesma língua é um dos estereótipos mais perigosos e um dos obstáculos à construção da lusofonia" (Lusa, 24/2/2011 - obs cit Paulino, 2015, p. 87-88), ou seja, como "geradora dum sentimento nacional multicultural imperialista em comum" (Dias, 2009, p7). Sobre o modo do "dever ser" lusófono, encontramos em Fiorin (2012.p. 21 apud BRITO, BASTOS \& BRIDI, 2016, p. 11):

\begin{abstract}
A lusofonia não será pátria, porque não será um espaço de poder ou de autoridade. Será mátria, porque deve ser um espaço dos sentimentos, e será frátria, porque deve ser o espaço dos iguais, que têm a mesma origem. Se assim não for, ela não terá nenhum significado simbólico real, será um espaço do discurso vazio de um jargão político sem sentido. Nesse caso, parafraseando Mário de Andrade, o melhor será esquecer Portugal e ignorar essa tal de lusofonia.
\end{abstract}

Todavia, no caso concreto de Timor-Leste, parece que alguns agentes cooperantes (nomeadamente daqueles que implementam o projecto de capacitação de cuja ação até agora não se vê concretamente o resultado) estão a entrar em ação com uma política de "imposição" aos professores timorenses para seguirem a sua política inapropriada nesta era da sociedade intercultural. Ser for assim, empresta a fala de Mário de Andrade, "o melhor será esquecer Portugal e ignorar essa tal de lusofonia” (obs cit BASTOS; BRITO \& BRIDI, 2016, p. 11). Ou seja, o que Portugal deu ao mundo, se não a sua própria imaginação de "ser grande" com lusofonia imaginária que nunca pode ser considerada como sua verdadeira pertença no meio de multiculturalismo. O que parece aqui, entretanto, é haver uma ausência de oportunidades ou estímulos sócio-culturais e económicos que produz o desânimo de vida na âncora do paradoxo, como lemos em:

foi na capital do império que eu montei a minha barraca / não consigo afastar a minha pistola, enquanto menino não conheci nenhuma escola, no liceu nunca vi / reformatório já fugi / Saramago nunca li / preparatório desisti, cantam os Phillarmonic Weed (Lança, 2010).

9 Marta Lança (2008), A lusofonia é uma bolha. Disponível em http://www.buala.org/pt/ jogos-sem-fronteiras/a-lusofonia-e-uma-bolha . Disponível em 15 mai. 2018.

PAULINO, V. Cartografia da lusofonia de língua portuguesa no mundo e em Timor-Leste 
Linha D'Água (Online), São Paulo, v. 32, n. 2, p. 145-167, maio-ago. 2019

Na presente descrição, observa-se que há um desconhecimento aos estímulos socioculturais. Neste caso, parece que qualquer modalidade de cooperação internacional (seja cooperação portuguesa ou qual for) no programa de capacitação e de investigação está sempre a pensar o "Outro" como sua parceria de trabalho, ao mesmo tempo, desvaloriza essa parceria e isso é que se chama "um multiculturalismo vazio" na cooperação. Certo é que parece existir uma única forma de pensar no "Outro" apenas para "explorar" com algumas reservas de assimilação10.

\section{Discurso sobre a lusofonia em Timor-Leste}

A escolha da língua portuguesa é um paradoxo, porque foi afirmada historicamente como língua de dominação, e agora é representada como instrumento de afirmação identitária dos timorenses para se diferenciarem com outros países vizinhos (PAULINO, 2011). É opção que os políticos timorenses adoptam e precisam de decidir uma língua para representar o país e o povo.

E finalmente ninguém fez abstenção na recolha do legado da antiguidade e assim se escolheu o rumo do estado soberano com a decisão de dizer sim ao português como língua oficial de Timor-Leste. Todavia, o discurso sobre a lusofonia em Timor-Leste sobressai no momento em que todos os políticos, os governantes, os dirigentes da sociedade civil mencionam a importância que a língua portuguesa tem para Timor-Leste e suas respectivas ligações com outros países da CPLP.

O discurso sobre a lusofonia em Timor-Leste é, sem dúvida, voltado à ontologia da palavra "consolidação", consolidar o saber de línguas estrangeiras como o português que agora pertence à alma dos timorenses. A razão pela qual acreditamos ser capaz de simbolizar a noção de lusofonia em Timor, de modo específico, o discurso sobre tal conceito é identificado no livro O Anjo do Timor de Sophia de Mello Breyner Andersen, que explicita a maneira como o povo timorense nela se insere (Nakagome, 2014) e nela que se agrupa um mar de culturas, como dizia Vicente Paulino no seu poema "Língua Portuguesa como um mar de culturas" (2018, p. 103-104):

10 Ibidem

PAULINO, V. Cartografia da lusofonia de língua portuguesa no mundo e em Timor-Leste 
O homem nasce e morre em um mar de culturas, fala de uma língua para além do seu ser.

Viaja com musicalidade de letras

Para formar um mar de flores no rio,

Aclamando numa só voz, língua é minha cultura.

(...)

Língua Portuguesa como mar de culturas, através dele descobre-se a torre de línguas.

Coberto pelo cheiro de sândalo, numa rocha de ilha distante

Junto do mar bravo oceano.

Embora o mar é bravo, caravelas carregam em si a cruz de lusitano imaginário.

E, o mel de letras aos povos de além, estranhos conhecidos, afinal homens como nós.

Os povos de além que foram aclamados pelos versos dos simples célebres poetas. Alí também Timor movido pela fragrância do sândalo, onde vê primeiro o sol nascendo.

No trecho destes versos, entende-se que na fala de Adriano Moreira: "o português não é nosso, mas já é nosso" desde Minho a Timor. Assim, "a lusofonia funciona e tem sua relevância" (PAULINO, 2011, p. 85).

Quanto à consolidação do português no seio da comunidade timorense é parte indispensável da escolha e da implementação no terreno. É uma necessidade a que os timorenses dão a máxima atenção com uma asserção política capaz de garantir a sua existência real na base como língua de ciência e de conhecimento, ou seja, a necessidade sobre a qual raramente refletem os que agem apenas por hábito. Uma vez que venha a construir um discurso lusófono dentro da política de consolidação, porém, fica evidente que aprender e difundir o português é "útil" para a vida e necessariamente bom para navegar no dicionário e na clínica da 
ciência. Uma vez que se fez a pergunta sobre os critérios de escolha do português é claro que se associa às dimensões históricas e culturais. O "modo certo" de usar o português é uma vez que unitário e indivisível - nas conversações das ruas, nos mercados, nos serviços públicos, na família, na igreja e nos média - começa a expandir-se de forma apropriada.

Aqui em Timor-Leste vamos pensar a língua portuguesa na "dimensão asiática"11 em prol da sua internacionalização no mundo. Trata-se de um discurso de "carácter operativo útil” da lusofonia em torno da estratégia política de difusão do português na Ásia, uma vez que Timor-Leste assume o papel de ser "centro de difusão" para trilhar a "dimensão asiática" na CPLP com o português. É por isso,

Saber línguas estrangeiras, ler os clássicos, tocar piano e de admirar Debussy, um sortido de extravagâncias para ornamentar uma excelente carta de apresentação. No fim seria a perfeita união entre duas culturas. A asiática representada pela minha pele de seda, os olhos rasgados, os cabelos pretos e a minha postura como uma deusa ou a de uma gata, e a europeia entendida na forma sedutora como poetas, pintores e músicos a representam, uma bailarina dançando ao sabor da cadência das palavras sussurradas (CARDOSO, 2007, p. 12).

Isto é uma forma de definir a "dimensão asiática” na percepção literária imaginada em busca de uma resposta útil sobre o sentido de cruzamento cultural de que Timor-Leste faz parte. É aqui que a história convive com o futuro, onde o milagre do Maubere (designação do nome timorense) faz brotar o sonho de todos timorenses a sentirem o sabor de vida que nunca é realizado. Nesta escala de "dimensão asiática" é que os timorenses podem fazer algo mais para além de suas expectativas, fazem fluir o português juntamente com outros falantes da região, como a China e Macau que já implantaram vários departamentos do ensino de Língua Portuguesa em suas universidades.

11 Este trecho "dimensão asiática" foi anunciado pelo Professor Benjamim de Araújo e Corte-Real no colóquio de língua portuguesa realizada no mês de Fevereiro de 2016, em Díli. Trata-se de uma afirmação que procura unir toda a forças da CPLP que a partir de Timor-Leste pode pensar na "dimensão asiática" do português.

PAULINO, V. Cartografia da lusofonia de língua portuguesa no mundo e em Timor-Leste 
Linha D'Água (Online), São Paulo, v. 32, n. 2, p. 145-167, maio-ago. 2019

Fazer fluir e ressoar o milagre mauberiano nesta região é uma forma de fazer trilhar a "representação duplicada" que nunca foi enunciada até ao presente. A relação do significante com o significado do dizer "o que falta agora é a dimensão asiática12" está a alojar-se agora num espaço em que Timor-Leste pode vir "a ser intermediário entre a CPLP e a região da Ásia e Pacífico”13; essa relação é assumida pela própria liderança timorense quando liderou a presidência da CPLP em 2014 a 2016, tendo, dentro no seu interior a capacidade de prever o futuro da língua portuguesa. É assim que se entende o sentido de "dimensão asiática" no quadro de representatividade da representação enquanto representável pela própria acção no lugar estabelecido entre a partilha de ideia de uma coisa e a ideia de uma outra, que prevaleceu há 500 anos, em Lifau (Oe-cussi), onde se cruzaram duas civilizações: a portuguesa cristã e a timorense. Essa fusão gerou uma identidade única nesta região Ásia-Pacífico.

\section{Aprender o português é uma questão de consciência nacional e patriótica}

Qualquer leitor está familiarizado com o conhecido termo "consciência nacional” e escritos correntes sobre a memória colectiva que se manifesta por alguns elementos culturais de um povo, como a língua e a religião. $\mathrm{Na}$ corrente da modernidade nota-se que a interpretação sobre a "consciência nacional" está cada vez mais revolucionária pela sua justificação de pertença a uma identidade comum. Certo é que o que se associa ao espírito de consciência nacional é a própria conviç̧ão de cada cidadão a afirmar-se como um ser único e diferenciador do outro, usando a fórmula de "emancipação" como uma celebração de uma consciência partilhada no quadro de relações dialógicas.

Os timorenses devem aprender a língua portuguesa, pois dizia Mari Alkatiri (dnoticia.pt, 10/6/2011): "ela não é do colonialismo mas língua do povo e não de

12 É uma alocução do Professor Benjamin de Araújo e Corte-Real no colóquio de língua portuguesa realizada no mês de Fevereiro de 2016, em Díli.

13 É opinião de Eládio António de Jesus (deputado da Fretilin) que recordou a importância do português para Timor-Leste - https://blog.lusofonias.net/? p=30247. Disponível em 15 mai. 2018.

PAULINO, V. Cartografia da lusofonia de língua portuguesa no mundo e em Timor-Leste 
qualquer regime político". É um elemento de afirmação da identidade cultural e nacional de Timor-Leste que está ligada à sua história. Aprender o português é uma consciência nacional de cada cidadão, porque aprender esta língua significa querer obter e saber alguns significados próprios na consolidação do nós em relação à história de construção do estado e da identidade nacional. É por isso que não se pode ficar constrangido com o uso da palavra consciência nacional, porque ela é apenas uma parte da definição de construção do estado, uma vez que é considerada como útil e bom para a manutenção da identidade cultural e nacional, agora claramente referida nos discursos políticos como um valor acrescentado na política de "influência intencional" para conquistar aquilo que é pertinente para a sociedade.

Mari Alkari (LUSA, 4/3/2015) falou ainda que "Se temos escolas de referência que estão a ter bons resultados, porque é que não ampliamos lentamente esse tipo de escolas, com o mesmo sistema de educação onde a língua portuguesa é usada como língua simultaneamente de ensino e de instrução desde a pré-escolar”. Rui Maria de Araújo, por sua vez, afirma que "Vamos todos apoiar esta ideia: Vamos todos dotar o Ministério da Educação de meios para poder ter professores em todas as escolas de Timor-Leste para ensinar português e em português" (Lusa, 7/5/2015) e não para implementar as línguas maternas. "Iremos, portanto, prosseguir os esforços e promover novas iniciativas no sentido de reforçar e promover a posição da língua portuguesa no sistema mundial, incluindo esforços de âmbito nacional, com a expansão do ensino da língua nas escolas de ensino privado, incluindo as escolas católicas e as universidades privadas" (Xanana Gusmão, in Lusa, 17/7/2014). É por isso "não há razão para não usar a língua portuguesa" (LOBATO, 2010 - obs cit PAULINO, 2018, p. 85).

Estas mensagens são resultado de reflexões que os políticos timorenses lançaram ao seu povo dizendo que a língua portuguesa é muito importante para Timor-Leste, e que com ela projecta ao mundo de ciência e de tecnologia. É portanto aprender a falar o português uma consciência nacional e patriótica, porque esta língua é um grande unificador da nação, ou seja, apropriar o português como língua de comunicação e de produção da ciência entre os falantes significaria que quanto à sua legitimidade no quadro de construção do estado é vista no momento 
Linha D'Água (Online), São Paulo, v. 32, n. 2, p. 145-167, maio-ago. 2019

em que desperta a coesão da sua existência dentro daqueles que usam como documento patrimonial de sua história.

Sendo assim, o problema de consolidação e de manutenção do português como língua de cultura e língua oficial de Timor-Leste dependerá muito da política educacional, da mobilização dos vários sectores da sociedade timorense, da disposição da comunidade e do apoio dos países lusófonos em construir o futuro comum que é, sem dúvida, a lusofoneidade no mundo (vide BRITO \& MARTINS, 2004; PAULINO, 2015) com a língua portuguesa e mais culturas diferenciadas de cada membro da CPLP, pois tem assumido outros papéis de extrema importância na comunidade lusófona, tais como: oferecer oportunidade igual ao acesso da educação e à inclusão e à paz social; fortificar os laços de amizade entre países membros da CPLP com a oferta de prestação dos serviços ao nível cultural, educativo ou de negócios na sociedade global; e incluindo a preservação dos usos e práticas culturais nas línguas com intuito de manter viva a sigla de - unidade na diversidade - para justificar que somos um povo enfeitado pela babel da língua e pela cultura, como então designada em posição de representação que emerge a afirmação de identidade nacional que viva nos versos de Luís de Camões que trouxeram Timor ao conhecimento do mundo ocidental: Alí também Timor que lenho manda; Sândalo salutífero e cheiroso. E, esta afirmação camoniana é uma consciência de reconhecimento e o fruto de uma evolução semântica que atravessa no tempo e isso fortifica a civilidade timorense no espaço e no mundo.

É com base nesse reconhecimento pautado no espírito de consciência nacional, que os indivíduos da comunidade nacional se afirmam como uma comunidade colectiva imaginada e se identificam como membros irmanados por laços e afinidades baseados na história e na cultura. Além disso, estas exprimem-se e revelam-se nas memórias, símbolos, mitos e heranças, e são posteriormente definidas como elemento de formação da comunidade de história, logo, a sua autenticidade é conferida pela validade de sua própria historicidade. Neste contexto, vale a pena realçar que o mais importante símbolo nacional é a língua. Assim, a língua não é em si mesma uma afirmação estática, mas, sobretudo, está ligada à dinamização do sentimento de pertença, muitas vezes partilhada com a etnicidade, a religião e a história comum. 
Linha D'Água (Online), São Paulo, v. 32, n. 2, p. 145-167, maio-ago. 2019

\section{Conclusão}

Devemos fazer o alargamento de cooperação bilateral e multilateral no âmbito da cultura e língua como factor de preponderância de Timor-Leste no quadro da CPLP na produção cultural e disseminação da mesma no espaço lusófono, europeu, asiático, no sentido de construir novas humanidades na cultura.

A cooperação com os agentes privados e as instituições culturais deve ser reforçada e baseada no mapeamento e síntese das informações culturais, a fim de orientar a selecção do património comum no repositório cultural e semântico traduzível da própria representação aparentemente universal.

Finalmente, a política de consolidação do português em Timor-Leste é, sem dúvida, marcada por uma agenda política chamada "agenda moral e responsabilidade pessoal e social”. Essa agenda política está a associar-se ainda com a articulação da razão e da experiência, pelo que é importante o discurso sobre a consciência nacional e a validação do discurso sobre a lusofonia. Essas duas ideias conceptuais podem criar a nova realidade em português.

\section{Referências}

BRITO, R.P. ; BASTOS, N.B \& BRIDI, M.V. Cultura, lusofonia e identidade: relações. In BRITO, R.P; BASTOS, N.B \& BRIDI, M.V (orgs). Estudos lusófonos: múltiplos olhares. São Paulo: Terracota, 2016, p. 7-20.

BRITO, R.P de \& MARTINS, M.L. Considerações em torno da relação entre língua e pertença identitária no contexto lusófono. In Anuário Internacional de Comunicação Lusófona, Braga: Universidade do Minho, 2004, p. 69-78.

; CAVALCANTE, M \& COSTA, L. Interação linguística em Timor-Leste: ações e reflexões. In BRITO, R.P; BASTOS, N.B \& BRIDI, M.V (orgs). Estudos lusófonos: múltiplos olhares. São Paulo: Terracota, 2016, p. 123-143.

CARDOSO, L. Crónica de uma travessia. A época do Ai-Dik-Funam. Lisboa: Dom Quixote, 2002. 


\section{Linha D'Água (Online), São Paulo, v. 32, n. 2, p. 145-167, maio-ago. 2019}

O ano em que Pigafetta completou a circum-navegação. Lisboa: Sextante, 2012.

Requiem para o navegador solitário. Lisboa: Dom Quixote, 2007.

CRISTÓVÃO; F. Uma academia das academias lusófonas para a língua portuguesa. In Ciberdúvidas da Língua Portuguesa, 2014. Disponível em <https:/ciberduvidas-iscte-iul.pt/artigos/ rubricas/lusofonias/uma-academia-das-academias-lusofonas-para-a-lingua-portuguesa/3084>. Acesso a 15/05/2018.

DIAS, I.C. Curating Contemporary Art and the Critique to Lusophonie. In Arquivos da Memória. Antropologia, Arte e Imagem, 5-6, Lisboa: Centro de Estudos de Etnologia Portuguesa, 2009.

FIORIN, J.L. Língua portuguesa, identidade nacional e lusofonia. In: BASTOS, N.B (org). Língua portuguesa - cultura e identidade nacional. São Paulo: EDUC - IP-PUC/SP, 2010.

FOUCAULT, M. A ordem do discurso. Lisboa: Relógio D’Água, 2007.

FREIXO, A. Minha pátria é a língua portuguesa: a construção da ideia de lusofonia em Portugal. Rio de Janeiro: Apicuri, 2009.

FREYRE, G. O mundo que o português criou. Lisboa: Livros do Brasil, 1940.

LANÇA, M. A lusofonia é uma bolha. In: Revista Jogos Sem Fronteiras, edições Antipáticas, 2008. Disponível em <http://www.buala.org/pt/jogos-sem-fronteiras/a-lusofonia-e-uma-bolha>. Acesso a 15/05/2018.

LOURENÇO, E. A Nau de Ícaro: Imagem e Miragem da Lusofonia. Lisboa: Gradiva, 1999. Lusofonia(s) hoje: Timor-Leste e a idealização de um espaço lusófono. In: MARTINS, M.L \& et al (eds). Interface da lusofonia. Braga: Centro de Estudos de Comunicação e Sociedade - Universidade do Minho, 2014, p. 41-60.

MARTINS, C.M. Resenha de Freixo. In: DELTA., 27 (1), 2011, p. 155-162.

MARTINS, M. L. Lusofonia e Luso-tropicalismo: equívocos e possibilidades de dois conceitos hiper-identitários. In: Visages d'Amérique Latine, 3, 2006.

PAULINO, V. Cartografia da lusofonia de língua portuguesa no mundo e em Timor-Leste Todo conteúdo da Linha D’Água está sob Licença Creative Commons Attribution-NonCommercial 4.0 International License 


\section{Linha D'Água (Online), São Paulo, v. 32, n. 2, p. 145-167, maio-ago. 2019}

Média digitais e lusofonia. In: MARTINS, M.L (coord)., Lusofonia e interculturalidade: promessa e travessia. Vila Nova Famalicã: Húmus, 2015, p. 27-56.

MARTINS, P. Da lusofonia: formulações teóricas e práticas. In: Sousa, I.C \& Correia, A.M (org). Lusofonia encruzilhadas culturais, $1^{\mathrm{a}}$ edição, Macau: Saint Joseph Academic Press, 2011, p. 24-32.

NAKAGOME, P.T. A lusofonia em Timor-Leste: entre o discurso e o projecto. In BAPTISTA, M.M \& MAIA, S.V (coords)., Colonialismos, Pós-Colonialismos e Lusofonias - Atas do IV Congresso Internacional em Estudos Culturais. Edição online, 2014, p. 80-86. Disponível em $<$ http://estudosculturais.com/congressos/ivcongresso/wp-content/uploads/2014/04/atas-PTfinal.pdf>. Acesso a 15/05/2018.

PAULINO, V. A lusofonia como uma comunidade imaginada no espaço da CPLP. In: VERITAS - Revista Científica da Universidade Nacional Timor Lorosa’e vol 3, n. 1 (p. 83-98), Díli: UNTL, 2015.

Cultura e Múltiplas identidades linguísticas em Timor-Leste. In SOUSA, I.C \& CORREIA, A.M (orgs). Lusofonia encruzilhadas culturais. Macau: Saint Joseph Academic Press, 2011, p. 70-87.

Currículo nacional de ensino de Timor-Leste como um problema a resolver. In FONSECA, S; BAPTISTA, M.C \& ARAÚJO, I.S.B (orgs). Desafios da educação em Timor-Leste: responsabilidade social. Díli: Unidade de Produção e Disseminação do Conhecimento - UNTL, 2018, p. 75-96.

Dimensão funcional e factual da língua portuguesa no mundo e em Timor-Leste. In: Guedes, Maria Denise (et al.) Professores sem fronteiras: pesquisas e práticas pedagógicas em Timor-Leste. Florianópolis: NUP/UFSC, 2015a, p. 29-51.

Poemas - leituras do mundo e da natureza. Díli: Casa Apoema, 2018.

Rotas de expansão marítima portuguesa e signo de um Timor sândalo com gente de culturas. In: RILP - Revista Internacional de Língua Portuguesa, n. 28/29, 2015, p. 17-37.

Timor nas rotas de trocas comerciais desde século XII até finais do século XIX. In: SARMENTO, C.M; GUIMARÃES, P \& MOURA, S (coord editorial)., Confluência de culturas 
Linha D'Água (Online), São Paulo, v. 32, n. 2, p. 145-167, maio-ago. 2019

no mundo lusófono. Campinas - Brasil: Associação das Universidades de Língua Portuguesa, 2017, p. 361-385.

SOUSA, Ivo Carneiro de. O bicho de lusofonia ainda não é de seda. In: Sousa, Ivo Carneiro de \& Correia, Ana Maria (org). Lusofonia encruzilhadas culturais. Macau: Saint Joseph Academic Press, 2011, p. 6-15.

SOUSA, V. Lusofonia(s) e 'portugalidade': uma impossibilidade. In: BRITO, R.P; BASTOS, N.B \& BRIDI, M.V (orgs). Estudos lusófonos: múltiplos olhares. São Paulo: Terracota, 2016, p. 31-63.

VANSPAUWEN, B.P. A importância de implementar uma noção de lusofonia na educação cultural e cívica em Portugal, argumentada por alguns músicos oriundos de países 'lusófonos' em Lisboa. In: Anuário Internacional de Comunicação Lusófona, p. 67-83.

VICENTE, G. Copilaçam de Todalas obras de Gil Vicente. Lisboa: Imprensa Nacional-Casa da Moeda, 1984.

Recebido em 11/05/2019.

Aprovado em 30/07/2019. 